\title{
Obstructive hydrocephalus as a result of giant cell tumor of the thoracic spine: A case report
}

\author{
CHENG-YU WEI ${ }^{1,2}$, SHUO-TSUNG CHEN ${ }^{3,4}$, HSU-CHIH TAI $^{1}$, WEN-BING WANG ${ }^{5}$, \\ CHI-CHU CHANG ${ }^{6}$, YAO-CHIN WANG ${ }^{7,8}, \mathrm{LI} \mathrm{WEI}^{9,10}$ and WOON-MAN KUNG ${ }^{1,5}$ \\ ${ }^{1}$ Department of Exercise and Health Promotion, College of Education, Chinese Culture University, Taipei 11114; \\ ${ }^{2}$ Department of Neurology, Show Chwan Memorial Hospital, Changhua 50008; \\ ${ }^{3}$ Department of Applied Mathematics; ${ }^{4}$ Department of Sustainability Research Center, Tunghai University, Taichung 40704; \\ ${ }^{5}$ Department of Neurosurgery, Lo-Hsu Foundation, Lotung Poh-Ai Hospital, Luodong, Yilan 26546; \\ ${ }^{6}$ Division of Cardiovascular Surgery, Department of Surgery, Feng Yuan Hospital, Ministry of Health and Welfare, \\ Taichung 42055; ${ }^{7}$ Department of Emergency Medicine, Min-Sheng General Hospital, Taoyuan 33044; \\ ${ }^{8}$ Graduate Institute of Biomedical Informatics, College of Medical Science and Technology, Taipei Medical University, \\ Taipei 11042; ${ }^{9} \mathrm{PhD}$ Program for Translational Medicine, College of Medical Science and Technology, \\ Taipei Medical University and Academia Sinica, Taipei 11529; ${ }^{10}$ Department of Neurosurgery, \\ Wan Fang Hospital, Taipei Medical University, Taipei 11696, Taiwan, R.O.C.
}

Received October 13, 2014; Accepted May 27, 2015

DOI: $10.3892 / \mathrm{ol} .2015 .3881$

\begin{abstract}
Giant cell tumors (GCTs) are rare bone tumors that account for $\sim 5 \%$ of all primary bone tumors. When GCTs occur in the spine, patients usually present with localized pain and neurological symptoms, such as radiating pain or hyperesthesia. In the current report, an unusual case of a GCT of the thoracic spine associated with hydrocephalus is described. A 48-year-old male presented with urinary retention, loss of sensation in the lower limbs and inability to walk. The patient eventually developed hydrocephalus combined with altered consciousness, indicated by an inability to follow simple commands. Magnetic resonance (MR) imaging demonstrated the presence of a soft tissue mass at the T2 level, and biopsy examination of the tissue confirmed that it was a GCT. The patient experienced a sudden loss of consciousness due to an acute episode of obstructive hydrocephalus. A ventriculoperitoneal shunting procedure was performed to treat the hydrocephalus, and the patient regained normal consciousness, although the paraplegia persisted. An MR examination performed 30 months following surgery demonstrated that the tumor size was stable, consistent with the slow growth that is characteristic of GCTs. Diagnosis of GCTs may be
\end{abstract}

Correspondence to: Dr Woon-Man Kung, Department of Exercise and Health Promotion, College of Education, Chinese Culture University, 55 Hwa-Kang Road, Yang-Ming-Shan, Taipei 11114, Taiwan, R.O.C.

E-mail: nskungwm@yahoo.com.tw

Key words: giant cell tumor, hydrocephalus, spinal tumor, cerebrospinal fluid, ventriculoperitoneal shunt challenging, and relies on radiographic and histopathologic findings. Although rare, acute hydrocephalus as a result of GCTs should not be excluded from a differential diagnosis.

\section{Introduction}

Giant cell tumors (GCTs) are rare bone tumors that account for $\sim 5 \%$ of all primary bone tumors (1). GCT cells have osteoclast-like properties, and tend to invade and dissolve healthy bone, become highly vascularized and develop further calcifications around the periphery of the tumor, but they rarely metastasize. GCTs are most frequently identified in the long bones, such as the distal femur or proximal tibia, and 2-5\% of GCTs occur in the spine (1). Spinal lesions often involve the body of the vertebra and may be accompanied by soft tissue swelling (1). Patients with GCTs usually present with localized pain and neurological symptoms, such as radiating pain or hyperesthesia. Si et al (2) presented the characteristic imaging findings of a series of 30 pathologically confirmed GCTs, of which 5 cases were located in the cervical spine, 15 in the thoracic spine and 10 in the lumbar spine. A total of 12 cases were located in the epidural space, causing spinal cord and/or nerve root compression. Characteristic X-ray and computed tomography (CT) imaging findings included an osteolytic and expansile lesion with a 'soap bubble' or purely lytic appearance. Furthermore, magnetic resonance imaging (MRI) findings included a well-defined and expansile mass with heterogeneous low-to-iso signal intensity on T2-weighted images. In a similar study, Kwon et al (3) reported the MRI findings in 10 cases of GCTs of the spine, which included 1 lesion at $\mathrm{C} 7$ and 3 lesions of the thoracic, lumbar and cervical spine, respectively. On MRI examination, 10 cases exhibited an expansile mass with heterogeneous low to intermediate signal intensity on the T2-weighted images, 9 cases exhibited 
A

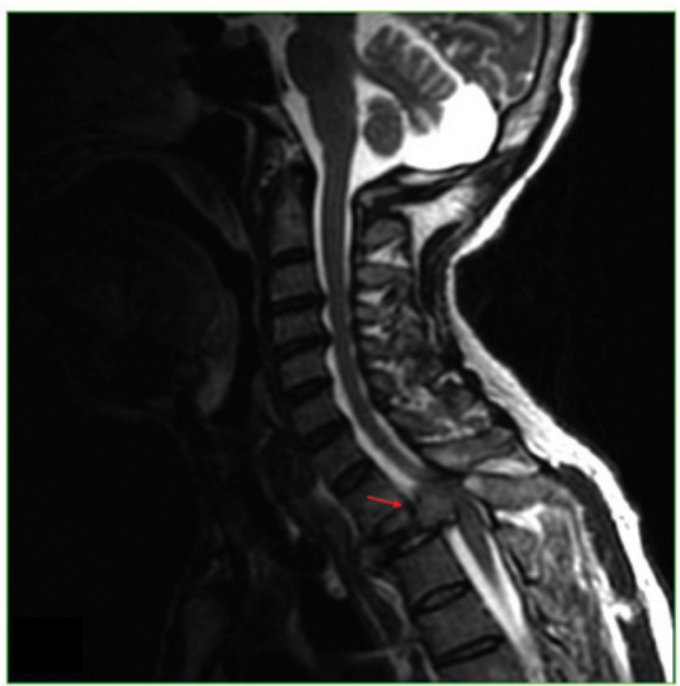

B

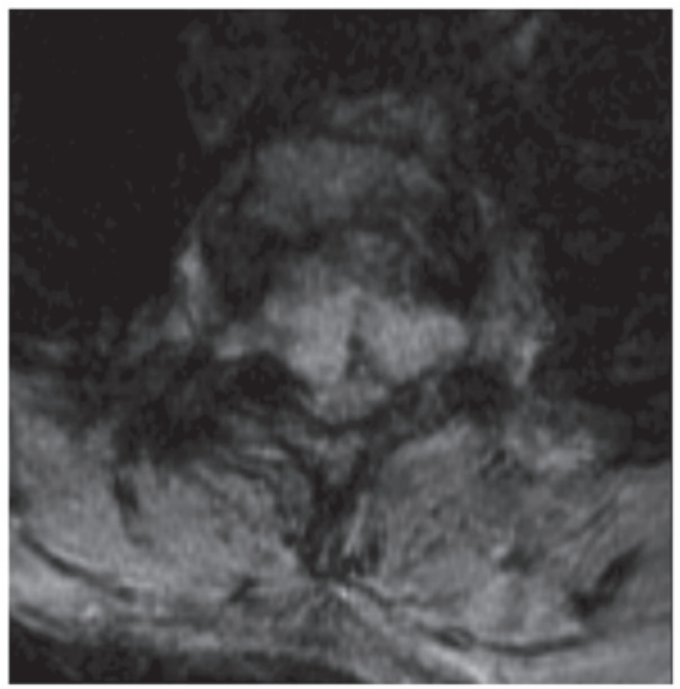

Figure 1. MR imaging of the spine of the patient at initial diagnosis (A) Sagittal T2-weighted MR image revealed a burst fracture with spinal canal involvement at the thoracic T2 level (arrow). (B) Axial T2-weighted MR image identified a tumor in the anterior, para- and retro-vertebral regions, associated with epidural invasion. MR, magnetic resonance.

a curvilinear area of signal void on T1- and T2-weighted images and 4 cases exhibited cystic changes within the mass. Martin et al (4) reported a series of 23 cases of GCTs of the sacrum and spine. The mean age at diagnosis was $\sim 35$ years, and the typical symptoms on presentation included pain and neurological deficits at the site of tumor involvement, with symptoms which had been present for a number of months prior to diagnosis. Treatments included arterial embolization, intralesional surgical resection and/or en bloc resection, and it was found that en bloc resection was associated with the lowest recurrence rate.

Surgery is the primary treatment strategy for GCTs; however, the recurrence rates range between 15 and $45 \%(5,6)$. En bloc wide resection is associated with lower recurrence rates than intralesional curettage (5 vs. $25 \%$ ), however, it carries a higher risk of morbidity (7). Treatment by intralesional curettage is typically accompanied by the application of phenol, polymethylmethacrylate, liquid nitrogen and bone grafting (8). Furthermore, radiation therapy may improve local control,
A

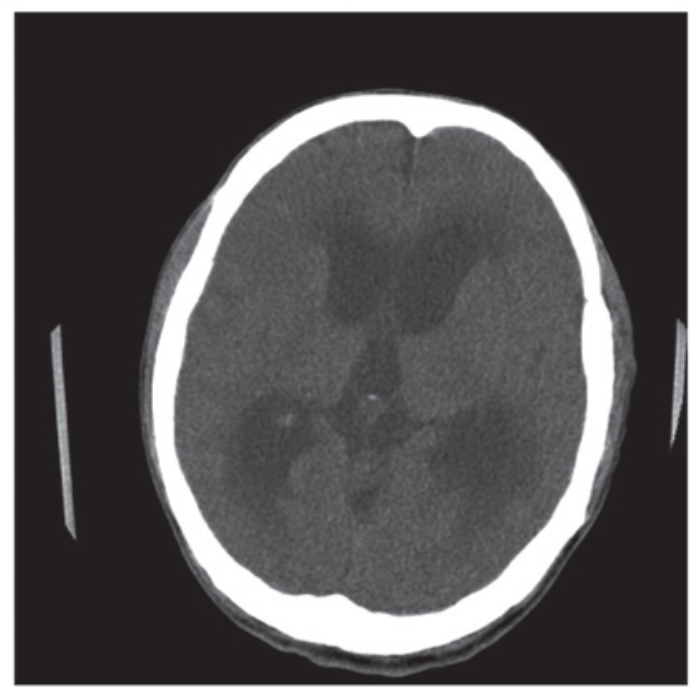

B

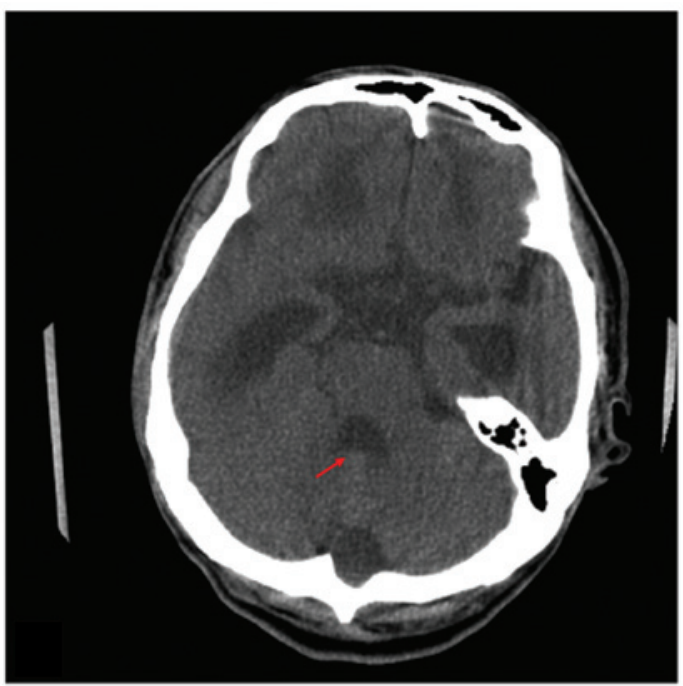

Figure 2. Computed tomography axial images of the brain 19 months subsequent to initial diagnosis. (A) Marked dilatation of the ventricles and transependymal cerebrospinal fluid resorption at the level of the lateral ventricle. (B) Dilation of the fourth ventricle (arrow). These findings indicate obstruction below the ventricular system.

but may also increase the risk of sarcomatous transformation $(9,10)$. No adequate medical therapies have been reported, although positive effects have been described in response to bisphosphonates (11), interferon $\alpha$ (12) and denosumab (13).

The current report describes an unusual case of a GCT of the thoracic spine in a middle-aged male in which obstructive hydrocephalus and alteration in consciousness developed 6 months after onset of the initial symptoms. The patient was treated with a ventriculoperitoneal shunt, however, surgery was not performed due to the size and location of the lesion. During 30 months of follow-up the size of the tumor remained unchanged. To the best of our knowledge, spinal GCTs have not been previously reported in association with hydrocephalus.

\section{Case report}

A 48-year-old male presented to the Department of Emergency Medicine, Wan Fang Hospital (Taipei, Taiwan) on September 17, 2007 with bilateral lower limb weakness. Over 
A

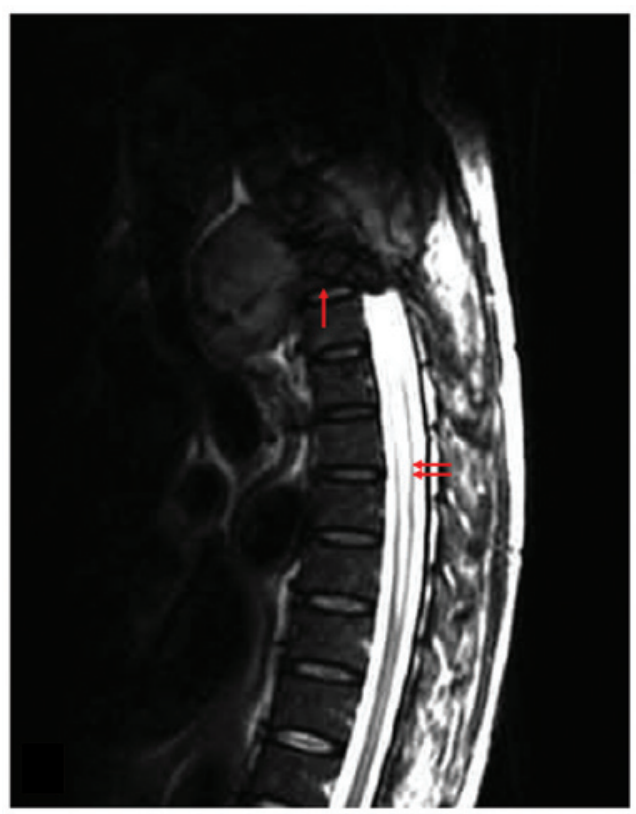

B

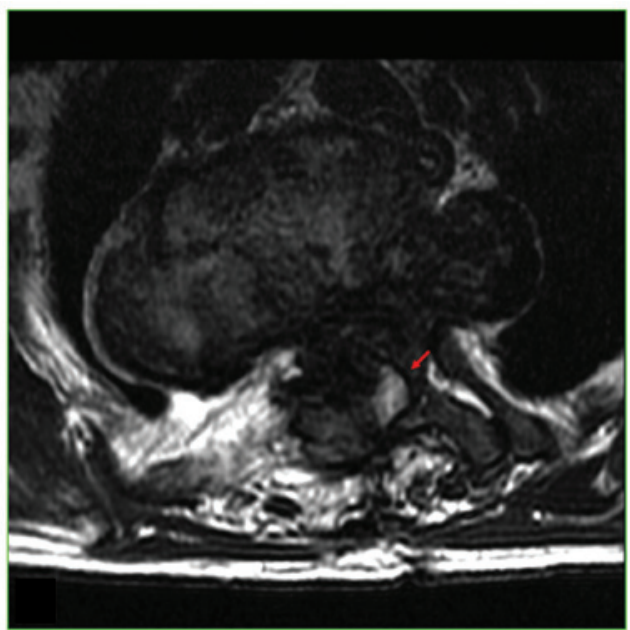

Figure 3. MR studies of the spine 19 months subsequent to initial diagnosis (A) Sagittal T2-weighted MR image demonstrated progressive change in tumor size (arrow) and the formation of syringomyelia (double arrow) (B) Axial T2-weighted MR image displayed a flattened spinal cord compromised by the enlarging tumor (arrow). MR, magnetic resonance.

1 week, the symptoms progressed rapidly, from loss of sensation below the thoracic level and urinary retention to bilateral lower limb weakness and the inability to walk. No history of major systemic diseases was recorded.Physical examination disclosed increased lower limb deep tendon reflexes, spastic gait with difficulty walking, sensory loss below the thoracic level and urinary retention, requiring the placement of a Foley catheter. Brain computed tomography (CT) without contrast, performed to discard intracranial conditions, indicated no abnormalities. A whole-spine magnetic resonance (MR) analysis indicated a compression fracture at $\mathrm{T} 2$ and a soft tissue mass with epidural invasion and central spinal stenosis (Fig. 1A). The soft tissue lesion was visible around the anterior-, para- and retro-vertebral regions (Fig. 1B). A gadolinium-enhanced MR analysis demonstrated iso-to-low T1- and T2-weighted images of the soft tissue mass. The symptoms were hypothesized to be a result of a $\mathrm{T} 2$ compression fracture possibly due to a

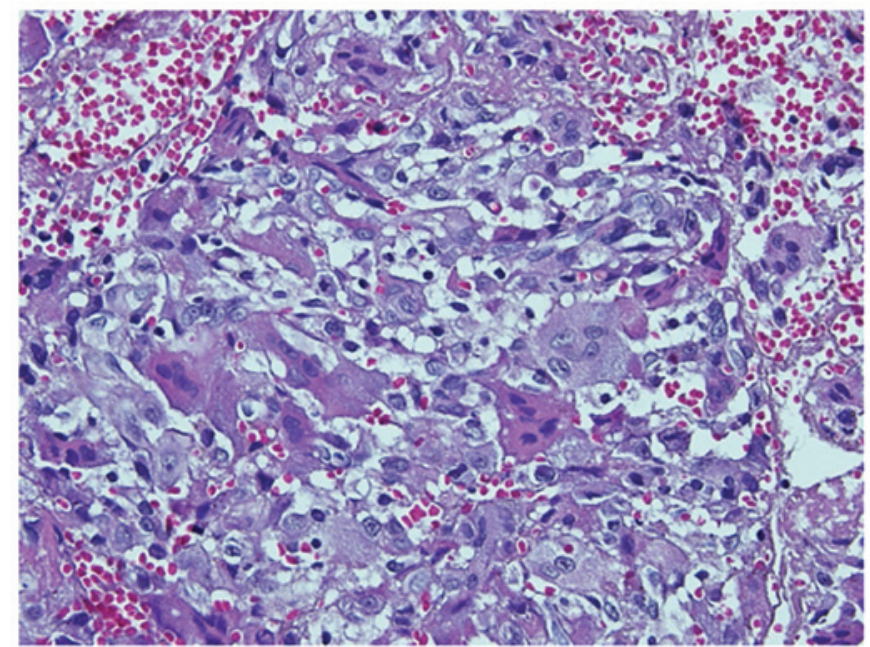

Figure 4. Histological examination of the tumor demonstrated numerous osteoclast-like multinucleated giant cells mixed with mononuclear ovoid stromal cells, consistent with a giant cell tumor (hematoxylin and eosin; magnification $\mathrm{x} 100$ )

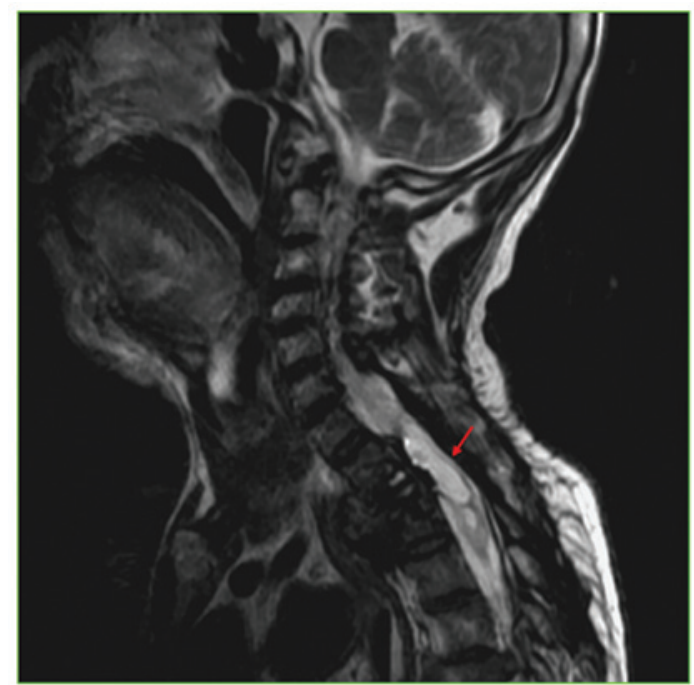

Figure 5. Mid-sagittal T2-weighted magnetic resonance image of the spine 30 months following initial surgery demonstrated syringomyelia (arrows) and stable tumor size.

bone tumor, metastasis or infection. Next, a T2 decompressive laminectomy was performed, and biopsy of the T2 vertebra under $\mathrm{C}$-arm fluoroscopy was attempted through the pedicles. However, no specific pathological findings were observed during the histological examination of the tissue, which revealed degenerated bony tissue, fibrocartilage and ligamentous tissues and marrow elements with normal maturation of hematopoietic cells, but no malignant tissue. Consequently, the patient was discharged 1 month later, and was able to ambulate using a walker. The patient and his family then decided to consult with a traditional healer, which is a common practice in Asian countries.

After $\sim 6$ months, the patient was readmitted to the Department of Emergency Medicine with a sudden onset of alteration in consciousness for an extended period of time in which the patient was unable to follow simple commands. Brain 
$\mathrm{CT}$ indicated marked dilatation of the ventricles, suggesting hydrocephalus (Fig. 2A). Low density of the periventricular area, possibly due to transependymal cerebrospinal fluid (CSF) resorption, was also noted. A gadolinium-enhanced MR analysis was performed to rule out distant metastasis of the tumor from the thoracic spine to the brain. However, no evidence of brain tumor was noted in the brain parenchyma. Marked dilatation of the ventricles, including the fourth ventricle, with transependymal CSF resorption, which is consistent with hydrocephalus, was observed (Fig. 2B). No evidence of acute infarction was detected in the diffusion-weighted image. An abnormally high-intensity T2-weighted signal was observed in the lower medulla and cervical cord, accompanied by swelling. CSF flow studies were quantitatively evaluated by measuring the peak velocity in the cerebral aqueduct using cine-phase contrast MR imaging. The maximum CSF velocity at the cerebral aqueduct of the patient was $12.3 \mathrm{~cm} / \mathrm{sec}$ (normal range, 4-5 cm/sec) (14), demonstrating abnormal hyperdynamic CSF motion.

Accordingly, the patient was diagnosed with marked hydrocephalus, possibly due to a lesion below the level of the cervical spinal cord. In order to confirm this hypothesis, MR imaging of the thoracic spine, with and without contrast enhancement, was performed (Fig. 3A and B). The study detected compression fractures at $\mathrm{T} 2$ and $\mathrm{T} 3$, and indicated that the previously identified soft tissue lesion had increased in size, extending from the anterior vertebral body towards the spinal canal. In addition, the formation of syringomyelia was observed.

Due to the progressive alteration in the spinal lesion, a CT-guided biopsy of the suspected thoracic spine tumor was performed. Macroscopically, the tissue was a soft, brown mass; microscopically, it was observed to contain numerous osteoclast-like multinucleated giant cells (that were evenly distributed) mixed with mononuclear ovoid stromal cells (Fig. 4). Neither cell type displayed nuclear atypia or mitosis, and minimal hemosiderin and lymphocyte infiltration were noted. Additionally, a small area of new bone formation was observed at x100 magnification. Immunohistochemical staining revealed the giant cells to be strongly positive for CD68, and the mononuclear cells to be focally positive for CD68 and smooth muscle actin. No cells were observed to be positive for cytokeratin or S-100. Histological and immunohistochemical studies were consistent with GCT.

Consultation with a chest surgeon eliminated the possibility of primary resection of the tumor due to the high surgical risk, secondary to the size and location of the lesion. Radiotherapy was suggested for management of the tumor, but the family hesitated due to the high risk of radiation myelitis.

A ventriculoperitoneal shunting procedure was performed to treat the hydrocephalus. CSF analysis was conducted intraoperatively during the shunting procedure. Visually, the CSF content appeared to have a clear color and non-viscous fluid flow. Microscopic examinations, including routine cell counts and biochemistry, were normal. No pleocytosis or high protein content were observed in the CSF, indicating no evidence of an inflammatory process.

Although the patient regained normal consciousness, the paraplegia persisted. The patient and his family declined further treatment due to religious beliefs; and the patient was discharged in order to consult with a traditional healer. The patient received a regular follow-up with MR examination of the spine 30 months subsequent to the initial surgery. The results demonstrated that the size of the tumor was stable (Fig. 5), which is compatible with the slow growth characteristic of GCTs.

Written informed consent was obtained from the patient for the publication of the present case report and any accompanying images.

\section{Discussion}

The majority of the spinal tumors reported in the literature are of neural lineage, including neurofibromas (15), schwannomas (15), oligodendrogliomas (15), astrocytomas (16), ependymomas (17), gliomas (18) and mixed glioneuronal neoplasms (19). GCTs are rare primary bone tumors that comprise $\sim 5 \%$ of all primary bone tumors (20). GCTs may occur in the vertebrae above the sacrum and in the sacrum (2.9 vs. $2.5 \%$, respectively) (21). Spinal lesions often involve the body of the vertebra, and patients with GCTs of the spine usually present with pain $(22,23)$. A subset of these patients may also report radiculopathic symptoms, varying degrees of myelopathy or other neurological symptoms, due to the compression of the spinal cord (1).

Diagnosis of GCTs of the spine may be challenging, and relies on diagnostic imaging and histopathological examination of tissue (24). When lesions occur in the thoracic spine and extend into the paraspinal soft tissue, they may be mistaken for a mediastinal mass (25). CT, MR imaging, scintigraphy and positron emission tomography are all valuable tools for the diagnosis of GCTs (25). Histologically, GCTs typically appear as uniformly distributed multinucleated giant cells against a background of round-to-spindle shaped mononuclear stromal cells (1).

GCTs are typically slow growing, non-metastasizing tumors, however, if left untreated after the initial onset of symptoms, spinal GCTs have been reported to metastasize (26-28). Thus, spinal GCTs are best treated promptly to avoid later metastasis or hydrocephalus. Treatment strategies for spinal GCTs include embolization, resection and radiation $(1,27)$.

The association of hydrocephalus with mass lesions affecting the spinal cord is unusual, but well-documented (25,29-31). To the best of our knowledge, the present case is the sole example of a non-neural spinal tumor associated with hydrocephalus, with the exception of 1 case involving an intramedullary lipoma (28). In the reports of hydrocephalus associated with neural tumors, hydrocephalus was usually the initial finding, and the spinal tumors were detected secondarily, often being identified by back pain that became evident following the resolution of the hydrocephalus (15). By contrast, spinal GCTs, including the present case, are initially detected due to sensory complaints and neurological impairments associated with the compression of the spinal cord (32). Thus, hydrocephalus should be considered a potential complication of spinal GCTs.

The majority of the explanations for the cause of hydrocephalus focus on the commonly observed elevation of CSF protein content, which may lead to occlusion of the arachnoid granulations or to retardation of the CSF flow by increased viscosity $(29,31)$. This increased concentration of protein has 
been attributed to tumor breakdown, hemorrhage and transudation through abnormal tumor vessels (31). Kudo et al (15) reviewed 67 cases of intraspinal tumors associated with hydrocephalus, and concluded that hydrocephalus is likely due to elevated protein content in the CSF, which decreases its absorption, and/or leads to mechanical blocking of the pores whereby the CSF is absorbed by the protein molecules. Schwartz et al (33) described a patient with severe communicating hydrocephalus due to a lumbar myxopapillary ependymoma. Kordás et al (34) presented 3 cases of hydrocephalus associated with spinal tumors, and postulated that the high protein content of the CSF resulted in malabsorption.

Although protein elevation in the CSF may be a possible cause for acute hydrocephalus with obstruction, this hypothesis remains controversial. Cinalli et al (35) analyzed 38 case reports of intramedullary low-grade glioma associated with hydrocephalus, and concluded that while an increase in the protein content in the CSF may be the cause of the hydrocephalus, the available evidence in the literature was not sufficient to support this theory. An alternative theory is that the hydrocephalus is caused by direct obstruction of CSF outflow by the large tumor bulk (36). In the present case, this obstruction occurred at the central canal of the spinal cord at the T2 level, due to the tumor. Obstructive hydrocephalus is occasionally observed with spinal tumors of neural origin, but is rarely observed with non-neural tumors $(15,31,36)$, such as the present case.

In the present case, CSF analysis was performed intraoperatively during the shunting procedure. Visually, the CSF content appeared to have a clear color and non-viscous fluid flow. Microscopic examinations of the CSF content, including routine cell counts and biochemistry, were normal. No pleocytosis or high protein content were observed in the CSF. Therefore 'elevated CSF protein' should not be problematic with the shunt in the present case report. However, postoperative long-term follow-up is required for the observation of the shunt function.

Kordás et al (34) proposed that other causes of hydrocephalus may include the presence of fibrinogen in the CSF, which may arise from the following events: i) A chronic inflammatory reaction; ii) loss of integrity of the blood-brain barrier; iii) acute or chronic subarachnoid bleeding from the tumor vessels; or iv) communication of the tumor and subarachnoid pathways. The presence of fibrinogen in the CSF may lead to deposition of fibrin and intracranial seeding of tumor cells that may block the CSF flow.

Spinal cord tumors may cause syringomyelia, as discussed by Lin et al (37) in a review of idiopathic syringomyelia. Based on the data in the present case, it was hypothesized that the hydrocephalus observed in the patient was the result of the thoracic spine giant cell tumor combined with syringomyelia. As the tumor increased in size, syringomyelia developed, leading to direct CSF outflow obstruction at the central canal of the cord. Management of symptoms includes the resection of the obstructing tumor, if possible, and the use of a shunt to reduce the intracranial pressure.

Characteristic symptoms of acute hydrocephalus include altered mental status, nausea/vomiting, headache and up-gaze palsy (Parinaud's syndrome) $(38,39)$. The diagnosis factors of acute hydrocephalus include a detailed history of the patient, physical and neurological examination (such as the level of consciousness and the cranial nerve function), radiographic studies that may include brain CT and/or MRI, CSF flow studies by cine-phase contrast MR imaging and CSF analysis $(14,40)$. Treatments for acute hydrocephalus include medical therapy and surgical management (for example, placement of a CSF shunt) $(38,40,41)$. Medical therapy is usually a temporary treatment strategy in transient conditions where CSF shunting is not suitable, such as central nervous system infections $(38,40,41)$. The use of medications as the final treatment for hydrocephalus is controversial, since they do not appear to be effective in the long-term treatment of chronic hydrocephalus $(40,41)$. A CSF shunt is the primary treatment for the majority of the etiologies of hydrocephalus in the adult and pediatric populations, and a ventriculoperitoneal shunt is the most commonly utilized procedure among all the shunting methods $(38,40,41)$. The current case presented with a sudden onset of alteration in consciousness, in which he was unable to follow simple commands, due to acute hydrocephalus as a result of a thoracic GCT, as confirmed by neuroimaging studies. A ventriculoperitoneal shunting procedure was immediately performed to treat the hydrocephalus, and the patient eventually regained normal consciousness, indicating the marked effectiveness of CSF shunting in the acute hydrocephalus in the current patient.

In summary, the present case report describes a unique case of a GCT of the thoracic spine in a middle-aged male that resulted in hydrocephalus. Diagnosis of GCTs may be challenging, and relies on radiographic and histopathologic findings. Although rare, acute hydrocephalus resulting from GCTs should be considered in the differential diagnosis of hydrocephalus.

\section{References}

1. Refai D, Dunn GP and Santiago P: Giant cell tumor of the thoracic spine: Case report and review of the literature. Surg Neurol 71: 228-233, 2009.

2. Si MJ, Wang CG, Wang CS, Du LJ, Ding XY, Zhang WB, Lu Y and $\mathrm{Zu}$ JY: Giant cell tumours of the mobile spine: Characteristic imaging features and differential diagnosis. Radiol Med 119: 681-693, 2014.

3. Kwon JW, Chung HW, Cho EY, Hong SH, Choi SH, Yoon YC and Yi SK: MRI findings of giant cell tumors of the spine. AJR Am J Roentgenol 189: 246-250, 2007.

4. Martin C and McCarthy EF: Giant cell tumor of the sacrum and spine: Series of 23 cases and a review of the literature. Iowa Orthop J 30: 69-75, 2010.

5. Chakarun CJ, Forrester DM, Gottsegen CJ, Patel DB, White EA and Matcuk GR Jr: Giant cell tumor of bone: Review, mimics, and new developments in treatment. Radiographics 33: 197-211, 2013.

6. Miller G, Bettelli G, Fabbri N and Capanna R: Curettage of giant cell tumor of bone. Introduction-material and methods. Chir Organi Mov 75 (Suppl): 203, 1990.

7. Klenke FM, Wenger DE, Inwards CY, Rose PS and Sim FH: Giant cell tumor of bone: Risk factors for recurrence. Clin Orthop Relat Res 469: 591-599, 2011.

8. van der Heijden L, Dijkstra PD, van de Sande MA, Kroep JR, Nout RA, van Rijswijk CS, Bovée JV, Hogendoorn PC and Gelderblom H: The clinical approach toward giant cell tumor of bone. Oncologist 19: 550-561, 2014.

9. Ruka W, Rutkowski P, Morysiński T, Nowecki Z, Zdzienicki M, Makula D, Ptaszyński K, Bylina E and Grzesiakowska U: The megavoltage radiation therapy in treatment of patients with advanced or difficult giant cell tumors of bone. Int J Radiat Oncol Biol Phys 78: 494-498, 2010.

10. Mittal S, Goswami C, Kanoria N and Bhattacharya A: Postirradiation angiosarcoma of bone. J Cancer Res Ther 3: 96-99, 2007. 
11. Tse LF, Wong KC, Kumta SM, Huang L, Chow TC and Griffith JF: Bisphosphonates reduce local recurrence in extremity giant cell tumor of bone: A case - control study. Bone 42: 68-73, 2008.

12. Kaban LB, Troulis MJ, Ebb D, August M, Hornicek FJ and Dodson TB: Antiangiogenic therapy with interferon alpha for giant cell lesions of the jaws. J Oral Maxillofac Surg 60: 1103$1111,2002$.

13. Dufresne A, Derbel O, Cassier P, Vaz G, Decouvelaere AV and Blay JY: Giant-cell tumor of bone, anti-RANKL therapy. Bonekey Rep 1: 149, 2012.

14. Giiang LH, Chen, CY, Chen MY, Huang TY, Chung WH: Normal and abnormal cerebrospinal fluid dynamics evaluated by optimized cine phase-contract MR imaging. Chin J Radiol 25:191-195, 2000.

15. Kudo H, Tamaki N, Kim S, Shirataki K and Matsumoto S Intraspinal tumors associated with hydrocephalus. Neurosurgery 21: 726-731, 1987.

16. Gelabert M, Bollar A, Paseiro MJ and Allut AG: Hydrocephalus and intraspinal tumor in childhood. Childs Nerv Syst 6: 110-112, 1990.

17. Kesler A and Manor RS: Papilloedema and hydrocephalus in spinal cord ependymoma. Br J Ophthalmol 78: 313-315, 1994.

18. Galarza M, Peretta P, Gazzeri R, Cinalli G, Forni M, Morra I, Ragazzi P and Sandri S: Spinal cord gliomas and hydrocephalus: Utility of neuroendoscopy. Minim Invasive Neurosurg 49: 347-352, 2006.

19. Psarros TG, Swift D, Mulne AF and Burns DK: Neurocytoma-like neoplasm of the thoracic spine in a 15-month-old child presenting with diffuse leptomeningeal dissemination and communicating hydrocephalus. Case report. J Neurosurg 103 (Suppl): 184-190, 2005.

20. Murphey MD, Nomikos GC, Flemming DJ, Gannon FH, Temple HT and Kransdorf MJ: From the archives of AFIP. Imaging of giant cell tumor and giant cell reparative granuloma of bone: Radiologic-pathologic correlation. Radiographics 21: 1283-1309, 2001.

21. Savini R, Gherlinzoni F, Morandi M, Neff JR and Picci P: Surgical treatment of giant-cell tumor of the spine. The experience at the Istituto Ortopedico Rizzoli. J Bone Joint Surg Am 65: 1283-1289, 1983.

22. Bhojraj SY, Nene A, Mohite S and Varma R: Giant cell tumor of the spine: A review of 9 surgical interventions in 6 cases. Indian $\mathrm{J}$ Orthop 41: 146-150, 2007.

23. Biagini R, De Cristofaro R, Ruggieri P and Boriani S: Giant-cell tumor of the spine. A case report. J Bone Joint Surg Am 72: 1102$1107,1990$.

24. Tokas ZO, Yilmaz B, Akakin A, Demir MK, Yapicier O, Onat E, Urgen K and Konya D: Rare solitary primary osseous lesions of the spine in adults; challenges in CT and MR imaging diagnosis with pathological correlation. J Neurol Sci Turk 32: 275-283, 2015.

25. Sakurai H, Mitsuhashi N, Hayakawa K and Niibe H: Giant cell tumor of the thoracic spine simulating mediastinal neoplasm. AJNR Am J Neuroradiol 20: 1723-1726, 1999.
26. Meyer A, Bastian L and Bruns F: Benign giant cell tumor of the spine: An unusual indication for radiotherapy. Arch Orthop Trauma Surg 126: 517-521, 2006.

27. Ozaki T, Liljenqvist U, Halm H, Hillmann A, Gosheger G and Winkelmann W: Giant cell tumor of the spine. Clin Orthop Relat Res 401: 194-201, 2002.

28. Takahashi T, Katano S, Ishikawa H and Nakano T: Aggressive clinical course of giant cell tumor arising from thoracic vertebra after a long latent period. Radiat Med 24: 534-537, 2006.

29. Ridsdale L and Moseley I: Thoracolumbar intraspinal tumours presenting features of raised intracranial pressure. J Neurol Neurosurg Psychiatry 41: 737-745, 1978.

30. Schijman E, Zúccaro G and Monges JA: Spinal tumors and hydrocephalus. Childs Brain 8: 401-405, 1981.

31. Zavala LM, Adler JR, Greene CS and Winston KR: Hydrocephalus and intraspinal tumor. Neurosurgery 22: 751-754, 1988.

32. Kim HS, Lee JE, Jung SS, Chon J, Yoon DH, Park YK, Cho EH: Spinal cord injury due to the giant cell tumor of the second thoracic vertebra: a case report. Ann Rehabil Med 37:269-273, 2013.

33. Schwartz NE, Rosenberg S and So YT: Action at a distance: A lumbar spine tumor presenting as trigeminal neuralgia. Clin Neurol Neurosurg 108: 806-808, 2006.

34. Kordás M, Czirják S and Dóczi T: The spinal tumour related hydrocephalus. Acta Neurochir (Wien) 139: 1049-1054, 1997.

35. Cinalli G, Sainte-Rose C, Lellouch-Tubiana A, Sebag G, Renier D and Pierre-Kahn A: Hydrocephalus associated with intramedullary low-grade glioma. Illustrative cases and review of the literature. J Neurosurg 83: 480-485, 1995.

36. Sun H and Tian H: Intraspinal tumors accompanied by hydrocephalus: Case report, systematic review, and discussion of treatment strategy. Neurologist 17: 342-345, 2011.

37. Lin JW, Lin MS, Lin CM, Tseng CH, Tsai SH, Kan IH and Chiu WT: Idiopathic syringomyelia: Case report and review of the literature. Acta Neurochir Suppl (Wien) 99: 117-120, 2006.

38. Lee TT, Uribe J, Ragheb J, Morrison G and Jagid JR: Unique clinical presentation of pediatric shunt malfunction. Pediatr Neurosurg 30: 122-126, 1999.

39. Koga H, Mori K, Kawano T, Tsutsumi K and Jinnouchi T: Parinaud's syndrome in hydrocephalus due to a basilar artery aneurysm. Surg Neurol 19: 548-553, 1983

40. Hamilton MG: Treatment of hydrocephalus in adults. Semin Pediatr Neurol 16: 34-41, 2009.

41. Bergsneider M, Miller C, Vespa PM and Hu X: Surgical management of adult hydrocephalus. Neurosurgery 62 (Suppl 2): 643-659, discussion 659-660, 2008. 